\title{
Modeling the Puzzle of Hepatitis C Epidemiology in Romania: A Pathway to Control
}

\author{
Henrique Lopes $^{1}$, Ricardo Baptista-Leite ${ }^{2}$, Diogo Franco ${ }^{1}$, Irina Eclemea ${ }^{3}$, Eugenia C. Bratu ${ }^{4}$, Florentina L. Furtunescu ${ }^{4}$, \\ Corina Silvia Pop ${ }^{5}$, Bogdan C. Pana ${ }^{4}$
}

1) Public Health Unit, Institute of Health Sciences, Catholic University of Portugal, Palma de Cima, Lisbon, Portugal

2) Faculty of Health, Medicine and Life Sciences, Maastricht University. Institute of Health Sciences, Catholic University of Portugal, Lisbon, Portugal 3) Elias Emergency University Hospital, Bucharest, Romania 4) Department of Public Health and Management, Carol Davila University of Medicine and Pharmacy, Bucharest, Romania

5) Department of Internal Medicine II and Gastroenterology, Emergency University Hospital, Carol Davila University of Medicine and Pharmacy, Bucharest, Romania

\section{Address for correspondence: Corina Silvia Pop \\ Department of Internal Medicine II and Gastroenterology, Emergency University Hospital, Carol Davila University of Medicine and Pharmacy, Bucharest, Romania cora.pop@gmail.com}

Received: 28.11.2019

Accepted: 10.06.2020

\section{ABSTRACT}

Background \& Aims: To combat hepatitis C virus (HCV) and achieve its elimination by 2030, the emphasis should be on public health policies. In this study, we investigated the dynamics of epidemiology of HCV in Romanian risk groups that are characterized by higher occurrence densities with the aid of The Let's End HepC (LEHC) project.

Methods: The LEHC project addressed the modelling of HCV epidemiology, being applied in several countries, one of which is Romania. The model comprised an integrated solution of public health policies focused on the disease, using Adaptive Conjoint Analysis and Markov chains systems. This tool allowed the quantitative evaluation of public health policies' impact, for every year until 2030, in five population groups: people who inject drugs (PWID), prisoners, individuals who have received blood products, children at risk for vertical transmission, and the remnant population.

Results: It appears that Romania was already making great efforts in the context of public policies, allowing the achievement of HCV elimination by 2028 if current policies were maintained. Through additional work and greater efforts in further implementing public policies, the LEHC model estimated the possibility of anticipating this outcome to 2026 .

Conclusion: The LEHC model estimated an anticipation of the HCV elimination year in Romania to be 2026 if the twenty-four health policies in the study are fully implemented and consistently maintained over the years.

Key words: hepatitis C - modeling - public policies - public health.

Abbreviations: ACA: adaptive conjoint analysis; DAA: direct antiviral agents; HCV: hepatitis C virus; ICS/ UCP: Healthcare Sciences Institute/Catholic University of Portugal; KOL: key opinion leaders; LEHC: Let's End HepC; NAB: National Advisory Board; NIPH: National Institute of Public Health; NIS: National Institute of Statistics; NPA: National Prison Administration; PWID: people who inject drugs; RIC: retain in care; SVR: sustained virologic response; Tx1: first treatment for chronic hepatitis C; Tx2: probability of an infected individual being retreated against $\mathrm{HCV}$ if already retained in care and previously treated.

\section{INTRODUCTION}

Historically, hepatitis C has been a disease with an enormous impact on populations at a worldwide level. It is a pathology that develops over many years and sometimes over decades, which obliges a strong mobilization of health services in terms of human resources, technologies and capital. According to the natural history of the disease [1], it has a predictable evolution. In some advanced situations, it may lead to liver hepatocellular carcinoma, representing the seventh cause of hepatic mortality worldwide [2]. There are significant costs associated with this pathology, such as liver transplants and indirect costs caused by the transmissibility of the disease.

Around ten population groups are considered at risk for hepatitis $\mathrm{C}$ virus (HCV) infection: aboriginal and indigenous communities, children at risk for vertical transmission, specific birth cohorts, hemodialysis patients, individuals coinfected with HCV and human immunodeficiency virus (HIV), people who inject drugs (PWID) [3-5], migrants from countries with high HCV prevalence rates, prisoners [6-8], people who have received blood products [9-10], war veterans, baby boomers and others [11-13].

Over the past thirty years, the epidemiological forecast has set $\mathrm{HCV}$ prevalence rates between $0.5 \%$ and $3.5 \%$ in European 
countries $[14,15]$, and in some countries outside Europe it is possible to find values between $7 \%$ to $8 \%$ [16]. However, successive epidemiological revisions have found lower $\mathrm{HCV}$ prevalence rates [17], whose values are between $0.2 \%$ and $1.5 \%$ in European countries [18].

Traditionally, Romania is identified as one of the countries where high prevalence values of HCV were historically predicted $[19,20]$. Therefore, it was chosen to integrate the country pool of the Let's End HepC (LEHC) project's first phase, which was developed by the Unit of Public Healthcare of Healthcare Sciences Institute/Catholic University of Portugal (ICS/UCP). In addition to Romania, other countries have also participated in the first phase of the LEHC project ("htttp:// www.letsendhepc.com/").

In this study, we investigated the dynamics of the epidemiology in risk groups that are characterized by higher occurrence densities: PWID, prisoners, people who received at least one blood transfusion or other blood-derived products, children who contracted the $\mathrm{HCV}$ infection from their mothers during pregnancy (vertical transmission) and the remnant population (the general population from which the aforementioned risk groups were excluded). This analysis was the foundation for an impact study related to the epidemiological dynamics of twenty-four public health policies in order to estimate annual results up to 2030, knowing that one of the Sustainable Development Goals [21] aims at eradicating $\mathrm{HCV}$ until that year.

\section{METHODS}

The modeling of epidemiological evolution was achieved by using Markov chains, allocating the aforementioned risk groups in a total of 1100 active branches. This method also integrated each of the health states that the patient might assume, over the various stages of the Cure Cascade, as well as the associated annual probability of transition from health status according to the article published by Salomon et al. [1] in 2003.

The model organised public health policies under a Cure Cascade reading, with each policy having different impact degrees according to data collected from Key Opinion Leaders (KOL) in the country, by resorting to a reading with an Adaptive Conjoint Analysis (ACA) inquiry system. Therefore, each policy impacted specific zones of the Markov chain, differentiating the forecasting results of the epidemiological model (further details in "Public Health Policies impact in HCV epidemiological modeling: a tool towards a microelimination path").

\section{Remnant population and vertical transmission}

The remnant population's demography was obtained by assessing the country's total resident population and live births, according to the Romanian National Institute of Statistics (NIS) and projections from Eurostat. The annual probability of death for both genders was estimated according to a life table reported by the National Institute of Public Health (NIPH) [22].

$\mathrm{HCV}$ incidence values were aligned with modeling studies $[19,23,24]$ that reported new cases of HCV infections in the country. For the years that were not possible to extract inputs, values were adjusted to follow the identified trend. As a result, low rates were considered since 1950, registering a gradual increase until 1999 and decreasing for the following years.

$\mathrm{HCV}$ incidence rates related to vertical transmission were also accounted for in the remnant population, representing the number of live births infected with HCV. Until 1998 no data were found regarding this epidemiological indicator in Romania. However, for the period 1999-2007, there is data related to non-A, non-B Hepatitis cases reported by the Public Health Directorates. For the following years, data were extracted from hospital reports.

Regarding the HCV prevalence, it was estimated that in 2008 this rate was close to $2.6 \%$ [19]. Likewise, since 1950, low rates were considered along with a gradual increase until 1999 and a decrease for the following years.

Up until 1998, it was assumed that the diagnose of hepatitis $\mathrm{C}$ was still not conducted, therefore it is considered $0 \%$. For the period 1999-2018, a cumulative diagnose rate of approximately $16 \%$ [20, 25-27] was considered, regardless of gender, age group and disease stage (as for blood products and prisoners' populations). Acknowledging that the remaining epidemiological indicators corresponded to the ones identified in an initial diagnosis phase, the year 1999 was assumed as the year in which data should be set.

To estimate the rate of people who were retained in care (RIC), a report by the Romanian Public Health Institute was consulted. According to this document, the number of patients who have been hospitalized was divided by the estimated number of people having hepatitis C in 2008, which resulted in a RIC rate of $9 \%$ [25], assumed as constant for the period 1999-2018.

In Romania, hepatitis $\mathrm{C}$ treatments were only made available in 2002. Despite treatments were only reimbursed for naive patients, all the diagnosed individuals were included in the first treatment for chronic hepatitis $\mathrm{C}(\mathrm{Tx} 1)$. This rate was initially assumed as 5\%, slightly increasing each year until $14.9 \%$ in 2009 [25], remaining constant until 2016. Since that year, this rate was considered to be close to $27.65 \%$ [28], for both genders and all the age groups.

The commercialization of direct antiviral agents (DAAs) treatments in Romania began by the end of 2015, with 2016 being the year at which data should be considered for Tx2 (probability of an infected individual being retreated against $\mathrm{HCV}$ if already RIC and previously treated). The rate of patients being retreated if RIC and who have been previously treated was determined by consulting the number of individuals declared as being treated with DAA therapies by the National Health Insurance House. Therefore, the Tx 2 rate for the period 2016-2018 was determined to be around $10.1 \%$, regardless of gender and age groups, only accounting for patients in the F4 disease stage (according to Metavir score).

Two studies $[29,30]$ were used to determine sustained virologic response (SVR) rates for patients who followed Tx1. A study that included a patient's cohort for the period between 2004-2008, mentioned that the SVR for naive patients was $59.56 \%$. Therefore, this value was assumed for the period 2002 2015 for these patients. Since 2016, SVR rates were assumed as $98 \%$. As for patients who presented a "compensated cirrhotic" or "decompensated cirrhotic" state, an SVR rate of $41.8 \%$ was 
assumed for the period 2006-2016 [31]. For the following years, the SVR rate was around $98,07 \%$, regardless of age group.

The SVR rate for patients in Tx2 was assumed as $98 \%$ for "non-cirrhotic", 99.25\% [28] for "compensated cirrhotic" and $0 \%$ for "decompensated cirrhotic", values that were considered to be constant for all the years in the period 2017-2030 regardless of the age group.

\section{People who inject drugs}

Until 1989 no data were found regarding the total number of PWIDs in Romania. However, during the referred period it was considered that there were 100 PWIDs each year, with a gender distribution of $74 \%$ for male individuals and $26 \%$ for females, according to the Romanian Anti-Drug Agency [32]. The demography of this population was calculated by using an indirect estimation, more specifically, a treatment multiplier [33] that was applied to the annual number of drug users admitted for treatment. For the period 1999-2007, the bibliographical source was a report by the Romanian Antidrug Agency [32,34] and for the following years a report from the Romanian National Institute of Public Health was also considered. For this period, the population distribution was estimated by applying the PWIDs population gender distribution observed in 2008. In order to calculate the demography projection of this population, the PWIDs prevalence observed in 2017 was used for the period 2018 2030. The annual number of male and female PWIDs was aligned according to estimates. As for background mortality, a constant standardized mortality ratio was considered for the PWIDs population [35]. The annual probability of death was estimated to be 6.3 and 16.7 times higher than the annual probability of death in the remnant population, for males and females respectively.

The annual number of newly infected PWID was estimated by considering the same $\mathrm{HCV}$ incidence rate that was found in Turkey and Hungary. These studies were conducted between 2013 and 2014, aiming to find the anti-HCV prevalence among PWIDs for less than two years [36].

HCV prevalence values for the period 2003-2017 were extracted from the National Antidrug Agency data [37]. Equal prevalence rates for both genders were assumed, with the exception of the period 2008-2012, in which the reported data were stratified by gender, with the same prevalence being applied to all age groups. For previous years to 2003, the prevalence was assumed to be the same as in that year, as well as to the years after 2017, in which prevalence values were also assumed to be the same as in that year.

The annual probability of diagnosis was assumed to be $0 \%$ before 1999. For the following years, the diagnosis rate was calculated by dividing the number of new PWIDs entering Opiate Substitution Therapy (OST) programs by the total number of estimated undiagnosed PWID. According to the National Antidrug Agency Report from 2017 [37], the probability of a PWIDs to be treated for HCV is very low, being a consequence of treatments only being available since the F2 Metavir.

The annual probability of an infected individual being retreated for $\mathrm{HCV}$ if already retained in care and previously treated is considered to be $0 \%$ for all the years, due to the fact that DAAs therapies were only available by the end of 2015 and access to treatment was also difficult for the Remnant Population, according to data from the Romanian National Health Insurance House.

Regarding the success rate of the patient's first and second treatments, no data was found regarding the number of PWIDs that have benefited from HCV treatments.

\section{Prisoners}

No data were found regarding the number of prisoners population before 1990, as a result, the values of that year were assumed to be the same as the ones for the period 1950-1989. Values for the period 2018-2030 were assumed to be equal to the ones from 2017, due to no projection reports having been found. The National Prison Administration (NPA) provided data for the period 2007-2017, with the average age structure being applied to the remaining years. In order to align the data provided by the NPA with the available data from the Romanian National Institute of Statistics (NIS) and published data from international databases, it was decided that reports from the NIS should be used while applying the age structure provided by the NPA. No data regarding deaths in prisons were found, as a result, the same probabilities of death used for the remnant population were applied in this population. Also, no available data regarding the number of new chronic cases of hepatitis $\mathrm{C}$ were found. Therefore, the results found in a study from Larney et al. [8] were applied for the prisoners population $\mathrm{HCV}$ Incidence with the same increasing and decreasing rate as for HCV prevalence. The NPA provided data regarding the number of existing cases per age group, for 2017. Applying the same age structure, prevalence values for the remaining years were estimated by applying a slight increase/decrease rate. The number of patients within prison hospitals was used to estimate RIC values, considering the cases of HCV infection applied to the estimated number of diagnosed individuals. No data were found regarding the number of prisoners who benefit from HCV treatments, but due to the lack of funds it is unlikely that prisoners have been included in the access conditions.

\section{Blood products population}

The blood products population consists of the total number of individuals that have received a blood transfusion at least once in their lifetime. No data were found regarding the frequency of piercing, tattoos or other circumstances. The demography of this population is based on data provided by the NIPH for the period 1990-2017, being represented as the total number of individuals, distributed by the age group. It was assumed that the population size for the years before 1990 and after 2017 was the same as in the structure represented in the referred years. The number of individuals that entered this population, in each year, was considered by accessing data from the NIPH being based on hospital reports. Moreover, no official statistical data were found regarding new patients receiving blood products. Therefore, it was assumed that most cases occurred in hospitals. Entries in the blood product population considered patients that appeared in one year and did not appear in the year before that. Values for the background mortality were assumed to be the same as the ones used for the remnant population. 
No data were found regarding HCV incidence in Romania's blood products population. However, a study about HCV incidence in hemodialysis patients reported a rate of $2.6 \%$ $[38,39]$. This value was as assumed as valid and applied to the new individuals entering this population, per year, regardless of gender and age groups. A decrease rate from 2006 per year, was assumed for the previous period until 1950 and for the period 2006-2018, given that HCV testing measures were implemented in blood products screening.

Similarly, no data was found regarding $\mathrm{HCV}$ prevalence in Romania's blood products population. It was assumed that after introducing HCV screening in blood products, individuals in this population had the same risk of infection as the ones in the remnant population [19], which was estimated according to a study [40] with blood donors in one county of Romania. In this study, HCV prevalence is reported as the proportion (\%) of new blood donors (first-time blood donors) who are infected with HCV, for the period between 2006 and 2011 [40]. Since HCV was only discovered in 1989 , HCV prevalence rates for the period 1990-2005, and the period 2012-2018 is considered to be the ones mentioned in the literature regarding the firsttime donators in Romania [41], applicable to both male and female, regardless of the age group.

In order to obtain RIC rates in Romania for the period between 1999 and 2018, the number of patients that received a blood transfusion at least once in their lifetime, within hospital facilities, were considered along with the application of infection rates to the estimated number of diagnosed individuals.

Having ever received a blood transfusion was not a criterion for inclusion or exclusion from treatment, but as no data was found on the background of patients regarding transfusion acts, the probability of treatments (Tx1 and Tx2) [28] and SVR were assumed to be the same as in the remnant population [29-31].

\section{RESULTS}

In Romania, model results for 2019 forecasted a total population of 20,382,443 individuals, with 284,395 being infected with $\mathrm{HCV}$ and an occurrence of 3,875 new cases. In 2019 forecasts showed that 164,659 individuals would be diagnosed, with 87,325 being linked to care, from which 41,705 would be under treatment and 2,083 cured cases were expected. As for the different liver disease stages, model results for this year showed that there would be 49,130 cases of compensated cirrhosis, 4,587 decompensated cirrhosis and 2,582 cases of hepatocellular carcinoma. In addition, 184 liver transplant cases were expected, as well as 2,608 liver-related deaths.

The LEHC model forecasted the HCV elimination year as being 2028, considering a total population of $19,406,784$ individuals in that year, from which 28,080 would be infected with $\mathrm{HCV}$ and 3,654 would be new cases. Considering the pool of HCV infected individuals, around 21,051 were predicted to be diagnosed and 16,351 being linked to care. In 2028, 6,686 individuals would be on treatment and 7,962 individuals should be cured. Concerning the different liver disease stages, the model forecasted 43,749 cases of compensated cirrhosis, 1,474 cases of decompensated cirrhosis and 959 cases of hepatocellular carcinoma. Due to the burden of disease, 43 liver transplants would be expected to be conducted and it was estimated 1,114 cases of liverrelated deaths.

Nonetheless, if health policies remain unchanged until 2030, the model estimates that there will be further improvements on most epidemiological indicators that were considered in the LEHC project.

According to the model, the estimates would be that HCV prevalence values would steeply decrease until 2026 and slightly decrease until 2030. Assuming the elimination line as $10 \%$ of the modeled HCV prevalence value in 2015, the WHO target would be achieved by 2028 (Fig. 1). The below-presented values considered the forecast of current policies in Romania remaining unchanged until 2030.

Modeled HCV prevalence values for the remnant population and vertical transmission would be expected to steeply drop until 2024-2025 and slightly decreasing until 2030 (Fig. 2). As for the blood products population HCV prevalence would also be expected to steeply drop until 2024-2025 and continue decreasing until 2030 (Fig. 3). HCV prevalence for the prisoners' population would be expected to decrease until 2030 but with no significant differences from year to year (Fig. 4). The forecast for the HCV prevalence evolution for the PWIDs population showed a gradual decrease until 2024, with minor differences from year to year until 2030 (Fig. 5).

\section{DISCUSSION}

Historically, research on hepatitis C progression has been conducted by using Markov chains over the natural history of the disease [42], published by Salomon et. al [1, 43], with

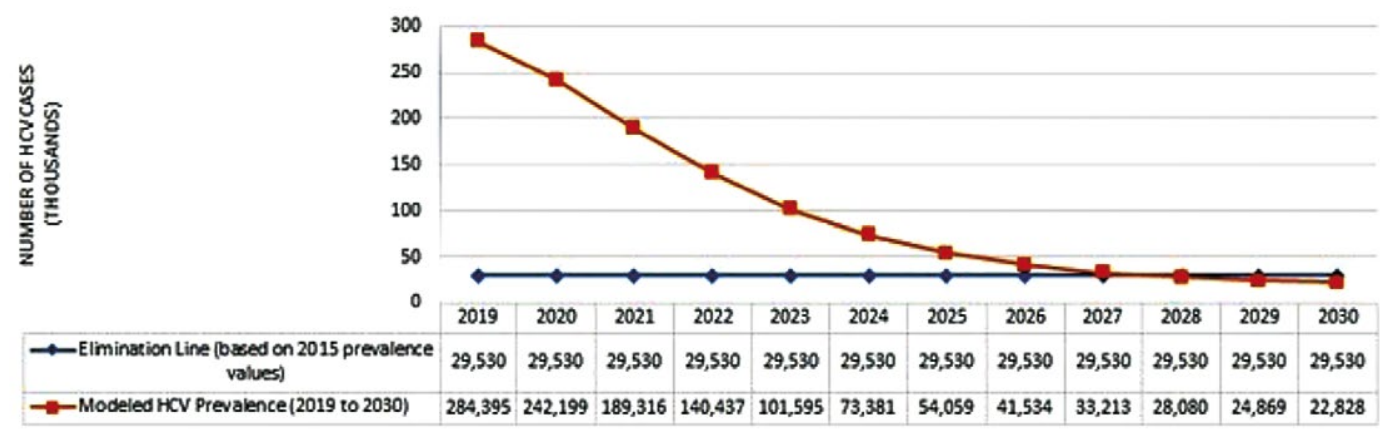

Fig. 1. Modeled HCV Prevalence of Total Population in Romania, 2019-2030. Comparison with elimination target for this population 


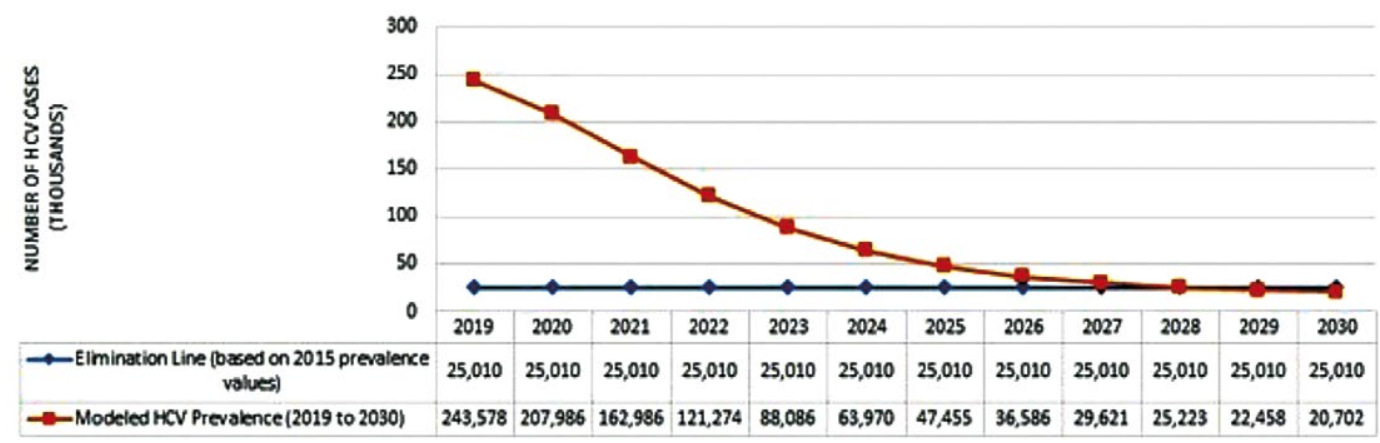

Fig. 2. Modeled HCV Prevalence for Remnant and Vertical Transmission Population in Romania, 2019-2030. Comparison with elimination target for this population.

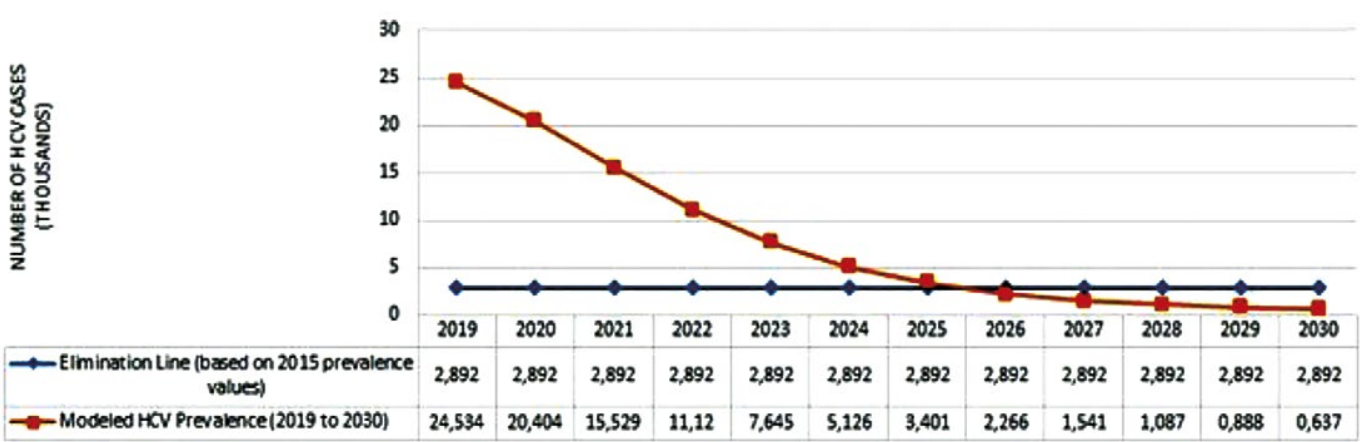

Fig. 3. Modeled HCV Prevalence for Blood Products Population in Romania, 2019-2020. Comparison with the elimination target for this population.

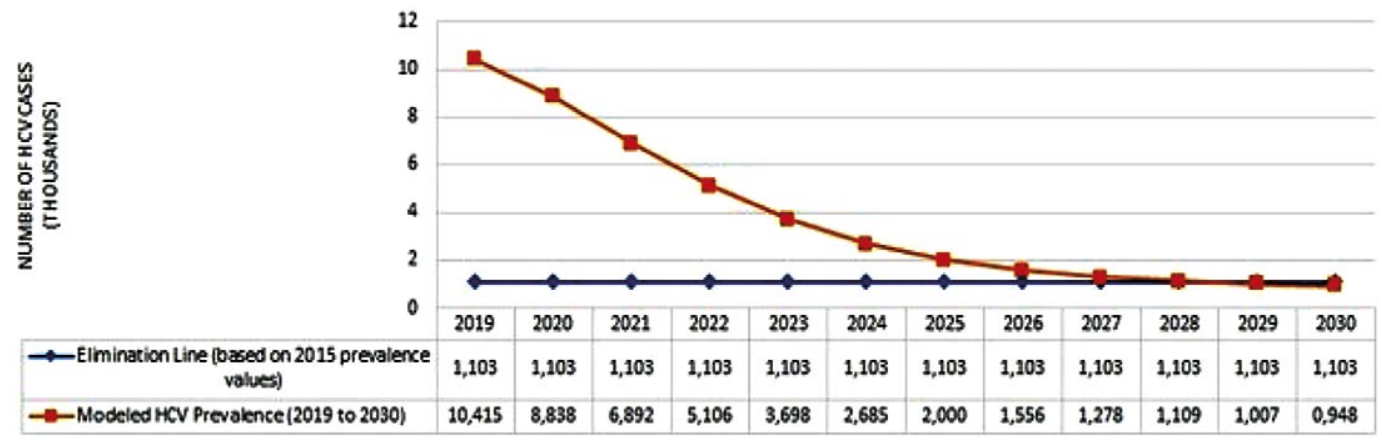

Fig. 4. Modeled HCV Prevalence for Prisoners and Ex-prisoners Population in Romania, 2019-2030. Comparison with the elimination target for this population.

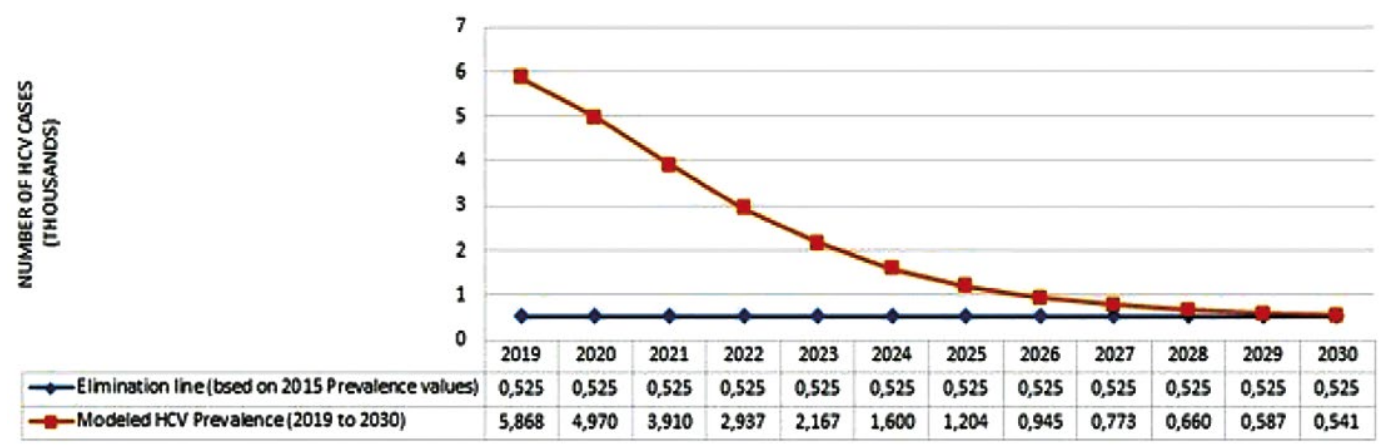

Fig. 5. Modeled HCV Prevalence for PWIDs and Ex-PWIDs Population in Romania, 2019-2030. Comparison with the elimination target for this population.

estimates on the disease progression, associated costs and the number of patients infected with HCV, by age and gender [44-46].
In May 2019 the National Framework Plan for viral hepatitis C control in Romania between 2019-2030 was formally released [47]. Specifically, this plan features different 
targets to be achieved in order to eliminate HCV in the country by 2030 in the following dimensions: vaccination; coverage for pregnancy testing for hepatitis B and C; coverage of the first dose of hepatitis B vaccin; post-exposure prophylaxis in infants born to infected mothers; all blood donations should be PCR tested for HBV and HCV infection; the continuity of risk reduction programs for people using injectable drugs (harm reduction), opioid substitute treatment; people living with chronic infection with HBV, VHD and HCV to be diagnosed and informed about their disease; people to be screened for $\mathrm{HBV}$ and HCV infection; people positive and eligible for treatment to be enrolled in antiviral treatment programs. With all the aforementioned policies and measures in place, it is estimated that hepatitis $\mathrm{C}$ will be eradicated in Romania by 2030 .

The other estimations for hepatitis C elimination year in high-income countries provide data ranging between 2024 in Spain, 2025 in France and 2049 in The Netherlands and Ireland [48]. Romania was not included in this analysis. The modelling in these countries do not integrate the impact of public health policies focused on hepatitis $\mathrm{C}$, thus it is not possible for direct comparison with data from the LEHC model. However, as soon as LEHC modelled results are available for the aforementioned countries, data will be published.

The LEHC project results appoint for the HCV elimination goal to be achieved by 2028 , according to data received by the 31st of December, 2018. These results consider the great efforts declared regarding the implemented public health policies focusing on hepatitis $\mathrm{C}$, its integral fulfilment and uninterrupted application until 2030.

However, it must be noted that the Let's End HepC epidemiological modeling tool integrates hepatitis $\mathrm{C}$ modeling with public health policies, in a unique solution. As there is no other estimating or modeling tool for hepatitis $\mathrm{C}$ that is able to integrate the effect of public health policies, it is not possible to establish a concurrent validity reading for Romania estimates. From a policy development perspective, the LEHC tool is a good measurement for calibration and the future will validate these predictions in the field.

This tool enabled the forecast of each policies impact, of the twenty-four considered in the LEHC project, on the epidemiological dynamics of hepatitis $\mathrm{C}$. Through quantitative analysis of the model results, it is now possible to test different applications of public health policies, anticipating possible results, supporting decision-making when applying them in a country's reality. The LEHC tool also allows information to citizens regarding the hepatitis $\mathrm{C}$ epidemiological traits in relation to public health policies, thus fostering hepatitis $\mathrm{C}$ advocating.

In the modelling process it is of the utmost importance to note that the rigor of any model will depend, first and foremost, on the quality of the underlying data, its analysis and field knowledge regarding the impact of public health policies in a given country.

\section{CONCLUSIONS}

According to the forecasted prevalence rates, if the current policies in Romania remain unchanged, the target of $\mathrm{HCV}$ infection elimination established by WHO is possible to be achieved by 2028 .

In Romania, it was established that twelve of the twentyfour policies have already been implemented according to the highest degree of our scale. This reading conveys the idea that there is an equal ratio of public health policies that can be further implemented, having the potential to achieve the WHO elimination goal by 2026 .

\section{Conflicts of interest: None to declare.}

Authors' contributions: H.L., R.B.L.: study concept and design. H.L., I.E., E.B.: data acquisition. H.L.: data analysis and study supervision. H.L., D.F.: drafted the manuscript and provided administrative support. H.L., R.B.L., B.P.: critical revised the manuscript for important intellectual content; F.F., C.P., B.P.: National Advisory Board; B.P.: coordinatated the Romanian LEHC team. All authors approved the final version of the manuscript for publication.

Acknowledgment: Contributions for the discussion of Romanian data on Hepatitis $\mathrm{C}$ and production of this article were received by the members of the Romanian LEHC National Advisory Board: Dana Minca, Liliana Gheorghe, Marinela Debu, Radu Ganescu, Adrian Streinu Cercel. Gilead Sciences Europe Ltd is providing financial support for the national data collection part of the modeling, webdesign and IT of the LEHC project.

\section{REFERENCES}

1. Salomon JA, Weinstein MC, Hammitt JK, Goldie SJ. Cost-effectiveness of Treatment for Chronic Hepatitis C in an Evolving Patient Population. JAMA 2003;290:228-237. doi:10.1001/jama.290.2.228

2. Stanaway JD, Flaxman AD, Naghavi M, et al. The global burden of viral hepatitis 1990 to 2013: findings from the Global Burden of Disease Study 2013. Lancet 2016;388:1081-1088. doi:10.1016/S0140-6736(16)30579-7

3. Degenhardt L, Peacock A, Colledge S, et al. Global prevalence of injecting drug use and sociodemographic characteristics and prevalence of HIV, HBV, and HCV in people who inject drugs: a multistage systematic review. Lancet Glob Health 2017;5:e1192-e1207. doi:10.1016/ S2214-109X(17)30375-3

4. Wiessing L, Ferri M, Grady B, et al. Hepatitis C virus infection epidemiology among people who inject drugs in Europe: A systematic review of data for scaling up treatment and prevention. PLoS One 2014;9:e103345. doi:10.1371/journal.pone.0103345

5. Robaeys G, Grebely J, Mauss S, et al. Recommendations for the management of HCV infection among people who inject drugs. Clin Infect Dis 2013;57 Suppl 2:S129-S137. doi:10.1093/cid/cit302

6. Kamarulzaman A, Reid SE, Schwitters A, et al. Prevention of transmission of HIV, HBV, HCV tuberculosis in prisoners. Lancet 2016;388:1115-1126. doi:10.1016/S0140-6736(16)30769-3

7. Snow KJ, Young JT, Preen DB, Lennox NG, Kinner SA. Incidence and correlates of HCV infection in a large cohort of prisoners who have injected drugs. BMC Public Health 2014;14:830. doi:10.1186/1471 2458-14-830

8. Larney S, Kopinski H, Beckwith CG, et al. Incidence and prevalence of hepatitis $\mathrm{C}$ in prisons and other closed settings: Results of a systematic review and meta-analysis. Hepatology 2013;58:1215-1224. doi:10.1002/ hep. 26387 
9. Kim A. Hepatitis C virus. Ann Intern Med2016;165:ITC33-ITC48. doi:10.7326/AITC201609060

10. Alter MJ, Kuhnert WL, Finelli L; Centers for Disease Control and Prevention. Guidelines for laboratory testing and result reporting of antibody to hepatitis C virus. Centers for Disease Control and Prevention. MMWR Recomm Rep 2003;52(RR-3):1-13.

11. Lazarus JV, Safreed-Harmon K, Thursz MR,et al.The MicroElimination Approach to Eliminating Hepatitis C: Strategic and Operational Considerations. Semin Liver Dis 2018;38:181-192. doi:10.1055/s-0038-1666841

12. Baker T. Chapter 22: Military Veterans and Hepatitis C. In: Caring Ambassadors Hepatitis C Choices. $4^{\text {th }}$ Edition. 2008:349-356.

13. U.S. Department of Health and Human Services. Centers for Disease Control and Prevention.Hepatitis C.Why baby boomers should get tested. Publication No. 220401, 2013. Available at:https://www. drugpolicy.org/sites/default/files/CDC_FactSheet-Boomers.pdf

14. Razavi H,Waked I, Sarrazin C, et al. The present and future disease burden of hepatitis C virus (HCV) infection with today's treatment paradigm. J Viral Hepat 2014;21 Suppl 1:34-59. doi:10.1111/ jvh. 12248

15. Thrift AP, El-Serag HB, Kanwal F. Global epidemiology and burden of HCV infection and HCV-related disease. Nat Rev Gastroenterol Hepatol 2017;14:122-132. doi:10.1038/nrgastro.2016.176

16. Elgharably A, Gomaa AI, Crossey MM, Norsworthy PJ, Waked I, TaylorRobinson SD. Hepatitis C in Egypt - past, present, and future. Int J Gen Med 2016;10:1-6. doi:10.2147/IJGM.S119301

17. Juanbeltz R, Pérez-García A, Aguinaga A, et al. Progress in the elimination of hepatitis $\mathrm{C}$ virus infection: A population-based cohort study in Spain. PLoS One 2018;13:e0208554. doi:10.1371/journal. pone. 0208554

18. World Health Organization (WHO). Global Hepatitis Report 2017. World Health Organization. 2017. Available at: https://apps.who.int/ iris/handle/10665/255016.

19. Gheorghe L, Csiki IE, Iacob S, Gheorghe C, Smira G, Regep L. The prevalence and risk factors of hepatitis $C$ virus infection in adult population in Romania: A nationwide survey 2006 - 2008. J Gastrointestin Liver Dis 2010;19:373-379.

20. Gheorghe L, Sporea I, Iacob S,et al. Position paper on treatment of hepatitis C in Romania 2017. Part two. J Gastrointestin Liver Dis 2017;26:309-317. doi:10.15403/jgld.2014.1121.263.rom

21. Baptista-Leite R, Lopes H, Vandewalle B, Félix J, Franco D. LEHC - Public Health Policies impact in HCV epidemiological modeling: a tool towards a micro-elimination pat. Preprint USP-ICS 2019/7 - Project LEHC. doi:10.13140/RG.2.2.32204.77443/1

22. Marcu A, Marcu M, Vitcu L, et al. Metode utilizate în monitorizarea stării de sănătate. Editura Institutului de Sănătate Publică București, 2002.

23. Gheorghe L. De la eradicarea la eliminarea (globala) VHC: Modelare pentru un Plan National de Eliminare in Romania pana in 2030. Bucuresti 2017. Available at: http://www.argumentpress.ro/wp-content/ uploads/2017/07/Prof.dr_.Liana-Gheorghe.pdf

24. European Union HCV Collaborators. Hepatitis C virus prevalence and level of intervention required to achieve the WHO targets for elimination in the European Union by 2030: a modelling study. Lancet Gastroenterol Hepatol 2017;2:325-336. doi:10.1016/S24681253(17)30045-6

25. Gheorghe L, Pascu O, Ceausu E, et al. Access to peginterferon plus ribavirin therapy for hepatitis C in Romania between 2002-2009. J Gastrointestin Liver Dis 2010;19:161-167.
26. Gheorghe L, Sporea I, Iacob S, et al. Position paper on treatment of hepatitis C in Romania, 2017. Part one. J Gastrointestin Liver Dis 2017;26:171-181. doi:10.15403/jgld.2014.1121.262.rom

27. Streinu-Cercel A. HCV Romanian framework- presentation held at the EU Parliament for the MEP Friends of the Liver meeting focusing on: The Challenge of Hepatitis C in Central and South Eastern Europe (22 March 2017). In: Viral hepatitis policies in Europe. Available at:https://epha.org/wp-content/uploads/2017/03/4.-Streinu-CercelHCV-Romanian-framework.pdf

28. Trifan A, Stanciu C, Gheorghe L, et al. Efficacy and safety of paritaprevir/ ritonavir, ombitasvir, and dasabuvir with ribavirin for the treatment of HCV genotype $1 \mathrm{~b}$ compensated cirrhosis in patients aged 70 years or older. Medicine (Baltimore) 2017;96:e9271. doi:10.1097/ MD.0000000000009271

29. Gheorghe L, Grigorescu M, Iacob S, et al. Effectiveness and tolerability of pegylated interferon $\alpha-2 \mathrm{a}$ and ribavirin combination therapy in Romanian patients with chronic hepatitis C: From clinical trials to clinical practice. Rom J Gastroenterol 2005;14:109-115.

30. Sporea I, Sirli R, Curescu M, et al. Outcome of antiviral treatment in patients with chronic genotype $1 \mathrm{HCV}$ hepatitis. a retrospective study in 507 patients. J Gastrointestin Liver Dis 2010;19:261-264.

31. Annicchiarico BE, Siciliano M, IacobellisA, et al. Sustained virological response prevents development and delays progression of portal hypertension in HCV-related liver cirrosis. J Hepatol 2010;52 Suppl 1:S101. doi:10.1016/S0168-8278(10)60241-3

32. National Antidrog Agency. Raport National Privind Situatia Drogurilor. REITOX 2007. Available at:http://ana.gov.ro/wp-content/ uploads/2018/11/raport-NATIONAL-2007.pdf

33. National Antidrug Agency. Raportul national privind situatia drogurilor. Romania - Noi evolutii si tendinte. REITOX 2014. Available at:http:/ ana.gov.ro/wp-content/uploads/2018/11/RO_RN_2014.pdf

34. European Monitoring Centre for Drugs and Drug Addiction. Romania - Country Drug Reports 2019. Available at:https://www.emcdda.europa. eu/countries/drug-reports/2019/denmark_en

35. Bargagli AM, Hickman M, Davoli M, et al. Drug-related mortality and its impact on adult mortality in eight European countries. Eur J Public Health 2006;16:198-202. doi:10.1093/eurpub/cki168

36. European Monitoring Centre for Drugs and Drug Addiction (EMCDDA). Hepatitis C among drug users in Europe: Epidemiology, treatment and prevention. 2016. doi:10.2810/967909

37. Agenţia Naţională Antidrog. Raport Naţional Privind Situația Drogurilor 2017: România Noi evoluţii şi tendinţe. REITOX2017. Available at:http://ana.gov.ro/wp-content/uploads/2019/09/RN_2018_20.12_site. pdf

38. Di Napoli A,Pezzotti P, Di Lallo D, et al. Epidemiology of Hepatitis C Virus Among Long-Term Dialysis Patients: A 9-Year Study in an Italian Region. Am J Kidney Dis 2006;48:629-637. doi:10.1053/j. ajkd.2006.07.004

39. European Centre for Disease Prevention and Control. ECDPC Technical report. Hepatitis B and C epidemiology in selected population groups in the EU/EEA. 2018. doi:10.2900/010358

40. Hâţu G, Brumboiu IM, Bocşan IS. HCV infection frequency and trends among voluntary blood donors in Cluj County (Romania) between 2006 and 2011. Clujul Med 2014;87:159-162. doi:10.15386/cjmed-301

41. Lieshout-Krikke RW, Domanovic D, De Kort W, et al. Selection strategies for newly registered blood donors in European countries. Blood Transfus 2017;15:495-501. doi:10.2450/2016.0107-16

42. Deuffic-Burban S, Poynard T, Sulkowski MS, Wong JB. Estimating the future health burden of chronic hepatitis $C$ and human 
immunodeficiency virus infections in the United States. J Viral Hepa 2007;14:107-115. doi:10.1111/j.1365-2893.2006.00785.x

43. Salomon JA, Weinstein MC, Hammitt JK, Goldie SJ. Empirically calibrated model of hepatitis $\mathrm{C}$ virus infection in the United States. Am J Epidemiol 2002;156:761-773. doi:10.1093/aje/kwf100

44. Wong JB, McQuillan GM, McHutchison JG, Poynard T. Estimating future hepatitis $\mathrm{C}$ morbidity, mortality, and costs in the United States. Am J Public Health 2000;90:1562-1569. doi:10.2105/ajph.90.10.1562

45. Razavi H,Elkhoury AC, Elbasha E, etal.Chronic hepatitis C virus (HCV) disease burden and cost in the United States. Hepatology 2013;57:21642170. doi:10.1002/hep.26218
46. Krauth C, Rossol S, Ortsäter G, et al. Elimination of hepatitis C virus in Germany: modelling the cost-effectiveness of HCV screening strategies. BMC Infect Dis 2019;19:1019. doi:10.1186/s12879-019-4524-Z

47. Coalition for Global Hepatitis Elimination. The Task Force for Global Health. National Frame Plan for the viral hepatitis control in Romania, 2019-2030, coordinated by the Ministry of Health Romania (National Program). Order 588/2019.

48. Razavi H, Sanchez Gonzalez Y, Yuen C, Cornberg M.Global timing of hepatitis $\mathrm{C}$ virus elimination in high-income countries. Liver Int 2020;40:522-529. doi:10.1111/liv.14324 